\title{
Insulin Resistance in Adult Primary Care Patients With a Surrogate Index, Guadalajara, Mexico, 2012
}

\author{
María Claudia Espinel-Bermúdez, MSc, * José Antonio Robles-Cervantes, PhD, * \\ Liliana del Sagrario Villarreal-Hernández, PhD, † Juan Pablo Villaseñor-Romero, MSc, $\dagger$ \\ Sandra Ofelia Hernández-González, PhD, * Manuel González-Ortiz, PhD,* \\ Esperanza Martínez-Abundis, PhD, $\neq$ and Karina Griselda Pérez-Rubio, MSc*
}

\begin{abstract}
Introduction: Insulin resistance (IR) is a key molecular disorder related with diabetes mellitus, obesity, and cardiovascular disease. The objective of this study was to determine IR in adult primary care patients using the triglyceride/glucose $(\mathrm{TyG})$ index [( $\mathrm{Ln} \mathrm{TG}(\mathrm{mg} / \mathrm{dL}) \times \mathrm{FG}(\mathrm{mg} / \mathrm{dL})) / 2]$. Methods: We conducted a cross-sectional secondary analysis and identified IR subjects according to the TyG index.

Results: There were 1500 patients included. Significant differences were found between the IR group versus the insulin-sensitive group, respectively: age (in years), $46.4 \pm 9.34$ versus $40.24 \pm 11.27(P<0.001)$; fasting glucose $(\mathrm{mg} / \mathrm{dL}), 99.87 \pm 11.95$ versus $84.62 \pm 6.59(P<0.001)$; total cholesterol $(\mathrm{mg} / \mathrm{dL}), 203.21 \pm 37.38$ versus $173.91 \pm 33.99(P<0.001)$; triglycerides $(\mathrm{mg} / \mathrm{dL}), 226.40 \pm 96.66$ versus $111.27 \pm 23.44(P<0.001)$; uric acid $(\mathrm{mg} / \mathrm{dL}), 6.09 \pm 1.59$ versus $4.77 \pm 1.40(P<0.001)$; and TyG index, $4.96 \pm 0.21$ versus $4.48 \pm 0.13(P<0.001)$. The cutoff of the TyG index for IR was 4.68 or greater.

Conclusions: The TyG index allows for early diagnosis of IR in primary health care.
\end{abstract}

Key Words: insulin resistance, the triglyceride/glucose index, primary health care

(J Investig Med 2015;63: 247-250)

nsulin resistance (IR) is a biochemical and molecular disorder strongly related with diseases such as obesity, diabetes, and cardiovascular disease. ${ }^{1}$ This close relationship between IR and other metabolic disorders has been associated with an atherogenic profile related with the activity of enzymes regulated by insulin. The most common clinical manifestation of IR is abdominal obesity. Therefore, central obesity has been considered as a fundamental part of the metabolic syndrome in which a necessary component is an increase in waist circumference correlated with an increase in visceral fat. Adipose tissue presents an

From the *Unidad de Investigación Médica en Epidemiología Clínica, Unidad Médica de Alta Especialidad, Hospital de Especialidades, Centro Médico Nacional de Occidente, IMSS; †Unidad de Medicina Familiar Número 3, Delegación Jalisco; and †Instituto de Terapéutica Experimental y Clínica (INTEC), Departamento de Fisiología, Centro Universitario de Ciencias de la Salud, Universidad de Guadalajara, Guadalajara, Jalisco, Mexico. Received August 5, 2014, and in revised form October 12, 2014

Accepted for publication October 31, 2014.

Reprints: José Antonio Robles Cervantes, PhD, Unidad de Investigación Médica en Epidemiología Clínica, Unidad Médica de Alta Especialidad, Hospital de Especialidades, Centro Médico Nacional de Occidente, IMSS, Guadalajara, Jalisco, México, Av. Chapalita 1300, Col. Chapalita, CP 45000, Guadalajara, Jalisco, México. E-mail: durun@megared.net.mx.

This is an open access article distributed under the terms of the Creative Commons Attribution-NonCommercial-NoDerivatives 3.0 License, where it is permissible to download and share the work provided it is properly cited.

The work cannot be changed in any way or used commercially.

Copyright (C) 2015 by The American Federation for Medical Research ISSN: 1081-5589

DOI: 10.1097/JIM.0000000000000130 important metabolic activity because its products (adipocytokines) have an interesting biological action on IR as well as endothelial, energy balance, and inflammatory function. ${ }^{2,3}$

Because IR is an intermediate metabolic disorder that can predict mortality in both patients with type 2 diabetes mellitus (T2DM) and those without diabetes, early detection during primary health care is important to decrease the incidence of cardiovascular disease. ${ }^{4}$ In this regard, the opportunity to detect IR is a challenge at this level of care. The criterion standard technique, which is the euglycemic-hyperinsulinemic clamp, is an invasive and expensive technique that is not feasible to implement on a large scale. ${ }^{5}$ Several indirect methods have been incorporated that allow estimating IR using the homeostatic model (HOMA-IR index) and the mathematical transformation of Quatitative Insulin Sensitivity Check Index, among others, ${ }^{6}$ which are methods that require insulin determination usually not feasible to process in primary health care units. Therefore, it is important to provide tools to general and family physicians that can be analyzed using basic and available biochemical studies. This will allow physicians to make timely decisions in relation to IR and to implement nonpharmacological actions required by patients who are at risk for developing T2DM and cardiovascular disease (CVD). ${ }^{7}$

Recently, Simental-Mendía et al. ${ }^{8}$ proposed a new formula for estimating IR from triglycerides (TG) and fasting glucose (FG), referred to as the triglyceride/glucose(TyG) index based on the product of the natural logarithm between TG and FG divided by 2 , whose formula is TyG $=[(\mathrm{Ln} \mathrm{TG}(\mathrm{mg} / \mathrm{dL}) \times \mathrm{FG}(\mathrm{mg} / \mathrm{dL})) / 2]$.

This formula was validated against the HOMA-IR index in an apparently healthy population. Later, the same group estimated the sensitivity and specificity of this index from 2 populations (healthy subjects and subjects with T2DM) versus the euglycemichyperinsulinemic clamp, obtaining a high sensitivity $(96.5 \%)$ and specificity $(85 \%)$ using a cutoff point of $4.68 .{ }^{9}$ With these findings, the primary care physician has a highly efficient substitute measure to establish a diagnosis. This will result in timely monitoring of the IR population with available and usual laboratory tests, thereby establishing the specific effects of therapeutic interventions before the patient presents impaired FG. The objective of our study was to determine IR in a primary care patient population using the TyG index and its behavior in the presence of other related biochemical markers.

\section{METHODS}

A cross-sectional secondary analysis was carried out using laboratory data of 1500 Mexican subjects who had routine tests carried out at the clinical laboratory department in a family medicine unit between January and August 2012. During the first stage, we excluded those subjects who did not have simultaneous FG and TG tests because these tests were fundamental for constructing the index to be evaluated. During the second stage, inclusion criteria were age between 20 and 59 years and without subsequent records during the study period. 


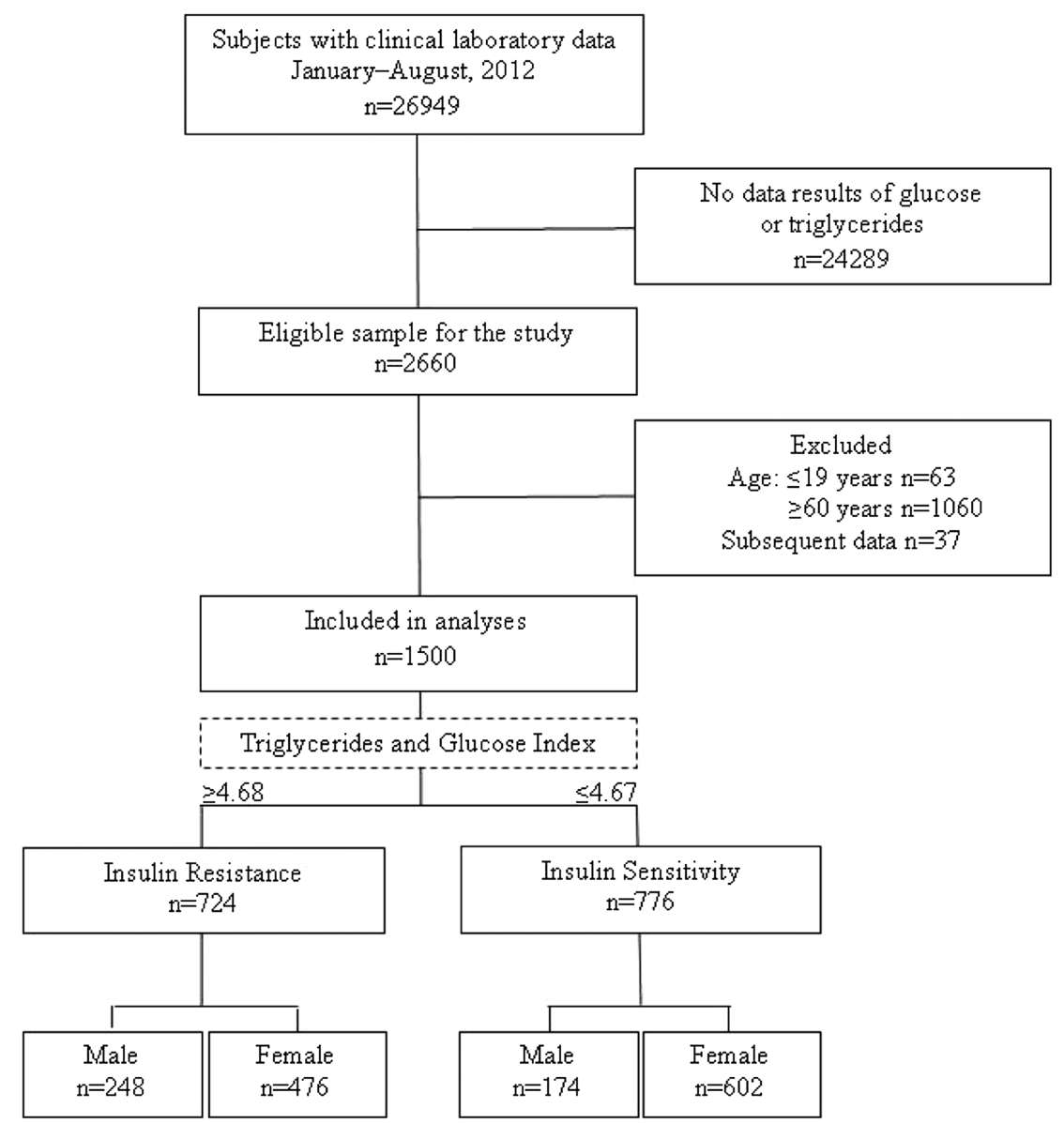

FIGURE 1. Flow chart of study subjects on laboratory databases to determine IR in adult primary care patients with a surrogate index $(n=1500)$, Guadalajara, Mexico 2012.

An analysis was done using laboratory determinations such as FG (mg/dL), total cholesterol (TC) $(\mathrm{mg} / \mathrm{dL})$, TG $(\mathrm{mg} / \mathrm{dL})$, creatinine $(\mathrm{mg} / \mathrm{dL})$, and uric acid (UA) (mg/dL). The index was constructed with IR subjects identified using a cutoff point of 4.68 or greater and insulin-sensitive (IS) subjects with an index of 4.67 or less. The variables were described according to their nature using measures of central tendency and dispersion as well as frequencies and percentages. The Student $t$ test was used to estimate

TABLE 1. Comparison of Insulin Resistance Group and Insulin-Sensitive Group Among 1500 Adult Primary Care Patients According to TyG index, Guadalajara, Mexico 2012

\begin{tabular}{lccr}
\hline Characteristic & IR $(\mathbf{n}=\mathbf{7 2 4})^{*}$ & IS $(\mathbf{n}=\mathbf{7 7 6})$ & \multicolumn{1}{c}{$\boldsymbol{P \dagger}$} \\
\hline Age, $\mathrm{y}$ & $46.40(9.34)$ & $40.24(11.27)$ & $<\mathbf{0 . 0 0 1}$ \\
Male/female, $\%$ & $34.3 / 65.7$ & $22.4 / 77.6$ & $<\mathbf{0 . 0 0 1}$ \\
FG, $\mathrm{mg} / \mathrm{dL}$ & $99.87(11.95)$ & $84.62(6.59)$ & $<\mathbf{0 . 0 0 1}$ \\
$\mathrm{TC}, \mathrm{mg} / \mathrm{dL}$ & $203.21(37.38)$ & $173.91(33.99)$ & $<\mathbf{0 . 0 0 1}$ \\
TG, $\mathrm{mg} / \mathrm{dL}$ & $226.40(111.27)$ & $96.66(23.44)$ & $<\mathbf{0 . 0 0 1}$ \\
Creatinine, mg/dL & $0.84(0.71)$ & $0.74(0.17)$ & $\mathbf{0 . 0 1 6}$ \\
UA, mg/dL $\ddagger$ & $6.09(1.59)$ & $4.77(1.40)$ & $<\mathbf{0 . 0 0 1}$ \\
TyG index & $4.96(0.21)$ & $4.48(0.13)$ & $<\mathbf{0 . 0 0 1}$
\end{tabular}

Values are expressed as mean (standard deviation).

*Cutoff point of 4.68 or greater.

$\dagger$ Significant difference using Student $t$ test or $\chi^{2}$ according to variable. The significance of the bold values is that $P \leq 0.05$.

$\ddagger$ Population analyzed for UA: IR $(n=230)$ and IS $(n=197)$.

FG indicates fasting glucose; IR, insulin resistant; IS, insulin sensitive; TC, total cholesterol; TG, triglycerides; TyG index, triglyceride/glucose index; UA, uric acid. 
TABLE 2. Analysis of Selected Variables According to Study Group and Sex Among 1500 Adult Primary Care Patients According to TyG index, Guadalajara, Mexico 2012

\begin{tabular}{|c|c|c|c|c|c|c|}
\hline \multirow[b]{2}{*}{ Characteristic } & \multicolumn{3}{|c|}{$\operatorname{IR}(n=724)$} & \multicolumn{3}{|c|}{ IS $(n=776)$} \\
\hline & Male $(n=248)$ & Female $(n=476)$ & $P^{*}$ & Male $(n=174)$ & Female $(n=602)$ & $P^{*}$ \\
\hline Age, y & $45.75(9.87)$ & $46.74(9.04)$ & 0.188 & $40.79(12.58)$ & 40.08 (10.87) & 0.500 \\
\hline $\mathrm{FG}, \mathrm{mg} / \mathrm{dL}$ & 100.89 (11.92) & $99.34(11.95)$ & 0.098 & $85.95(7.06)$ & $84.24(6.41)$ & 0.004 \\
\hline $\mathrm{TC}, \mathrm{mg} / \mathrm{dL}$ & $199.55(38.56)$ & 205.03 (36.68) & 0.072 & $170.71(35.37)$ & $174.85(33.54)$ & 0.161 \\
\hline $\mathrm{TG}, \mathrm{mg} / \mathrm{dL}$ & $247.29(129.12)$ & 215.51 (99.14) & 0.001 & $96.48(23.14)$ & $96.71(23.54)$ & 0.908 \\
\hline Creatinine, $\mathrm{mg} / \mathrm{dL}$ & $1.05(1.12)$ & $0.74(0.32)$ & 0.001 & $0.94(0.21)$ & $0.69(0.11)$ & 0.001 \\
\hline $\mathrm{UA}, \mathrm{mg} / \mathrm{dL} \dagger$ & $6.85(1.52)$ & $5.55(1.41)$ & 0.001 & $6.19(1.37)$ & $4.30(1.06)$ & 0.001 \\
\hline TyG index & $5.00(0.22)$ & $4.94(0.20)$ & 0.001 & $4.49(0.13)$ & $4.48(0.13)$ & 0.442 \\
\hline
\end{tabular}

Values are expressed as mean (standard deviation).

*Significant difference using Student $t$ test. The significance of the bold values is that $P \leq 0.05$.

$\dagger$ Population analyzed for UA: IR $(\mathrm{n}=230)$ and IS $(\mathrm{n}=197)$.

FG indicates fasting glucose; IR, insulin resistant; IS, insulin sensitive; TC, total cholesterol; TG, triglycerides; TyG index, triglyceride/glucose index; UA, uric acid.

between-group differences and the $\chi^{2}$ test was used for comparison of dichotomous variables; $P \leq 0.05$ was considered significant.

\section{RESULTS}

A total of 1500 patients from a total of 2660 subjects who had laboratory tests done during the study period were included in the study, of which $71.9 \%$ were females and $28.1 \%$ males. The FG (mg/dL) was $91.98 \pm 12.23$; TC $(\mathrm{mg} / \mathrm{dL}), 188.07 \pm 38.55$; $\mathrm{TG}(\mathrm{mg} / \mathrm{dL}), 159.28 \pm 102.28$; creatinine $(\mathrm{mg} / \mathrm{dL}), 0.79 \pm 0.50$; UA $(\mathrm{mg} / \mathrm{dL}), 5.48 \pm 1.64$; and TyG index, $4.71 \pm .29$. According to the cutoff point of the TyG index of 4.68 or greater, frequency of IR participants was $48.3 \%$ versus $51.7 \%$ of the IS subjects (Fig. 1).

When both groups were compared, a significant difference was demonstrated between the IR group versus the IS group, respectively, in age ( $46.4 \pm 9.34$ years vs $40.24 \pm 11.27$ years $)(P<$ $0.001), \mathrm{FG}(\mathrm{mg} / \mathrm{dL})(99.87 \pm 11.95$ vs $84.62 \pm 6.59)(P<0.001)$, $\mathrm{TC}(\mathrm{mg} / \mathrm{dL})(203.21 \pm 37.38$ vs $173.91 \pm 33.99)(P<0.001), \mathrm{TG}$ $(\mathrm{mg} / \mathrm{dL})(226.40 \pm 111.27$ vs $96.66 \pm 23.44)(P<0.001)$, creatinine $(\mathrm{mg} / \mathrm{dL})(0.84 \pm 0.71$ vs $0.74 \pm 0.17)(P=0.016), \mathrm{UA}(\mathrm{mg} / \mathrm{dL})$ $(6.09 \pm 1.59$ vs $4.77 \pm 1.40)(P<0.001)$, and TyG index $(4.96 \pm$ 0.21 vs $4.48 \pm 0.13)(P<0.001)$ (Table 1$)$. The behavior was similar when both groups were compared according to sex (Table 2).
Table 3 also provides an analysis with a cutoff point for UA of $6.4 \mathrm{mg} / \mathrm{dL}$. There were differences between IR and IS patients according to FG, creatinine, TG, and UA, but not with the TyG index. Finally, we conducted a logistic regression (Table 4) between the metabolic and demographic parameters and the TyG index to analyze the better association. The UA had the strongest association with TyG with an odds ratio of $4.44(P<$ 0.001 ), then with TC (odds ratio, 3.41; $P<0.001$ ).

\section{DISCUSSION}

When adult primary care patients were studied in our population, we observed a high frequency of IR (51.7\%). This intermediate metabolic marker is of great use because it allows for the detection of a high-risk population for CVD before a diagnosis of T2DM, ${ }^{4}$ which would support making medical decisions toward preventive and timely interventions to populations with factors related to alterations of the glucose/insulin relationship. Our results are similar to those reported by other groups. In fact, there is a wide range of frequency of IR depending on the population being studied. ${ }^{10}$ It is of interest that, during a primary care visit, feasible tools such as the TyG index be used, which has an acceptable correlation with the criterion standard of -0.67 and with a sensitivity of $96.5 \%$ and a specificity of

TABLE 3. Behavior of IR and Selected Variables According to Uric Acid $\geq 6.4 \mathrm{mg} / \mathrm{dL}$ Among 427 Adult Primary Care Patients According to TyG index, Guadalajara, Mexico 2012

\begin{tabular}{|c|c|c|c|c|c|c|}
\hline \multirow[b]{2}{*}{ Characteristic } & \multicolumn{3}{|c|}{$\operatorname{IR}(n=230)$} & \multicolumn{3}{|c|}{ IS $(n=197)$} \\
\hline & $\mathrm{UA} \leq 6.3(\mathrm{n}=144)$ & $\mathrm{UA} \geq 6.4(\mathrm{n}=86)$ & $P^{*}$ & $\mathrm{UA} \leq 6.3(\mathrm{n}=172)$ & $\mathrm{UA} \geq 6.4(\mathrm{n}=25)$ & $P^{*}$ \\
\hline Age, y & $47.60(9.29)$ & $46.50(9.51)$ & 0.244 & $41.34(10.85)$ & $45.36(12.54)$ & 0.156 \\
\hline $\mathrm{FG}, \mathrm{mg} / \mathrm{dL}$ & $98.49(12.21)$ & $101.85(12.38)$ & 0.050 & $83.71(6.51)$ & $86.80(7.60)$ & 0.053 \\
\hline $\mathrm{TC}, \mathrm{mg} / \mathrm{dL}$ & $202.46(36.45)$ & $205.61(40.97)$ & 0.453 & $176.01(34.66)$ & $162.12(28.75)$ & 0.061 \\
\hline $\mathrm{TG}, \mathrm{mg} / \mathrm{dL}$ & $216.72(108.38)$ & $247.83(108.65)$ & 0.010 & $96.81(24.34)$ & $105.36(18.05)$ & 0.061 \\
\hline Creatinine, $\mathrm{mg} / \mathrm{dL}$ & $0.72(0.14)$ & $0.91(0.19)$ & 0.001 & $0.71(0.12)$ & $1.04(0.34)$ & 0.001 \\
\hline $\mathrm{UA}, \mathrm{mg} / \mathrm{dL}$ & $5.14(0.88)$ & $7.69(1.18)$ & 0.001 & $4.38(0.99)$ & $7.43(0.85)$ & 0.001 \\
\hline TyG index & $4.93(0.21)$ & $5.02(0.20)$ & 0.744 & $4.48(0.13)$ & $4.55(0.08)$ & 0.098 \\
\hline
\end{tabular}

Values are expressed as mean (standard deviation).

*Significant difference using Student $t$ test. The significance of the bold values is that $P \leq 0.05$.

FG indicates fasting glucose; IR, insulin resistant; IS, insulin sensitive; TC, total cholesterol; TG, triglycerides; TyG index, triglyceride/glucose index; UA, uric acid. 
TABLE 4. Relationship Between TyG Index and Select Parameters

\begin{tabular}{lccr}
\hline Select Parameters & Odds & $\mathbf{9 5 \%}$ CI & \multicolumn{1}{c}{$\boldsymbol{P}$} \\
\hline Sex $($ male $)$ & 0.67 & $0.35-1.27$ & 0.224 \\
Age $(\geq 40 \mathrm{y})$ & 1.38 & $0.77-2.45$ & 0.267 \\
UA $(\geq 6.4 \mathrm{mg} / \mathrm{dL})$ & 4.44 & $2.08-9.47$ & $<\mathbf{0 . 0 0 1}$ \\
TC $(\geq 200 \mathrm{mg} / \mathrm{dL})$ & 3.41 & $1.97-5.92$ & $<\mathbf{0 . 0 0 1}$ \\
Creatinine $(\geq 1.2 \mathrm{mg} / \mathrm{dL})$ & 0.31 & $0.07-1.28$ & 0.107 \\
\hline
\end{tabular}

$\mathrm{CI}$ indicates confidence interval; TC, total cholesterol; UA, uric acid.

The significance of the bold values is that $P \leq 0.01$.

$85 \%$ and that allows the physician to stratify IR patients with the cutoff point of the TyG index of 4.68 or greater and who have a greater risk for developing the mentioned comorbid conditions. ${ }^{9}$ In our IR population studied, the difference in the behavior of variables such as FG, TC, TG, and even UA is noteworthy, which we found that the IR population has too much higher frequencies than the IS population has. The UA sparks new interest because, independent of the metabolic profile, it is associated with the development of T2DM, a fact seen in prospective studies in populations with hyperuricemia where the probably mechanism is at the $\beta$-cell level, which produces disorders in insulin secretion. ${ }^{11,12}$ In our population, despite the fact that males had greater UA concentrations, there were no differences with respect to females when the TyG index was used because TG and FG for both sexes were very similar (Table 3); however, the UA had the strongest association with TyG, with an odds ratio of 4.44 (Table 4). On the other hand, TG explains in large part the result of the TyG index, even greater than glucose, so its increase is accompanied by an increase in variables such as glucose and UA. The relationship of hypertriglyceridemia and IR with the consequent glucose elevation is already known. In vitro studies have suggested the possibility that high TG concentrations rich in very low density lipoprotein particles could impede the action of insulin by inhibiting insulin receptor binding, both at the hepatic and muscular levels. Intracellular accumulation of diacylglycerol triggers activation of protein $\mathrm{C}$ kinase with consequent impairment in insulin receptor signaling. ${ }^{13,14}$ The mechanism of the association between hypertriglyceridemia and UA is not fully understood. It has been observed that the synthesis of fatty acids in the liver is associated with the de novo synthesis of purines, which accelerates the production of UA. ${ }^{15}$ Nevertheless, our design does not allow for establishing a causal relationship in this regard. Finally, the TyG index has demonstrated that it correlated with the risk for coronary disease greater than $10 \%$ when compared with the Framingham risk equation. However, its ability to identify metabolic syndrome in epidemiological studies is not superior to other substitutes such as the McAuley index or the Stumvoll index. ${ }^{16}$

The TyG index allows establishing an early diagnosis of IR in primary health care that correlates with components such as FG, TC, TG, and UA.

These are useful for first-contact identification of an at-risk population for development of T2DM and CVD.

\section{ACKNOWLEDGMENTS}

The authors thank Dr. Carlos Diaz for his support in the preparation of this study.

The authors also thank Sharon Morey, an executive editor in scientific communications, for her English editorial assistance.

\section{REFERENCES}

1. Singh B, Saxena A. Surrogate markers of insulin resistance. A review. World J Diabetes. 2010;1(2):36-47.

2. Kershaw EF, Flier JS. Adipose tissue as an endocrine organ. J Clin Endocrinol Metab. 2004;89(6):2548-2556.

3. Goosengs GH. The role of adipose tissue dysfunction in the pathogenesis of obesity-related insulin resistance. Physiol Behav. 2008;94(2):206-218.

4. Ausk KJ, Boyko EJ, Ioannou GN. Insulin resistance predicts mortality in nondiabetic individuals in the US. Diabetes Care. 2010;33(6):1179-1185.

5. DeFronzo RA, Tobin JD, Andres R. Glucose clamp technique: a method for quantifying insulin secretion and resistance. Am J Physiol. 1979;237(3):E214-E223.

6. González-Ortiz M, Martínez-Abundis E. Comparison of several formulas to assess insulin action in the fasting state with the hyperglycemic-hyperinsulinemic clamp technique in healthy individuals. Rev Invest Clin. 2003;55(4):419-422.

7. Mercurio V, Carlomagno G, Fazio V, et al. Insulin resistance: is it time for primary prevention? World J Cardiol. 2012;4(1):1-7.

8. Simental-Mendía LE, Rodríguez-Morán M, Guerrero-Romero F. The product of fasting glucose and triglycerides as surrogate for identifying insulin resistance in apparently healthy subjects. Metab Syndr Relat Disord. 2008;6(4):299-304.

9. Guerrero-Romero F, Simental-Mendía LE, González-Ortiz M, et al. The product of triglycerides and glucose, a simple measure of insulin sensitivity. Comparison with the euglycemic-hyperinsulinemic clamp. $J$ Clin Endocrinol Metab. 2010;95(7):3347-3351.

10. Esparza-Romero J, Valencia ME, Martínez ME, et al. Differences in insulin resistance in Mexican and U.S. Pima Indians with normal glucose tolerance. J Clin Endocrinol Metab. 2010;95(11):E358-E362.

11. Scott FW, Trick KD, Stradric B, et al. Uric acid-induced decrease in rat insulin secretion. Proc Soc Exp Biol Med. 1981;166(1):123-128.

12. Robles-Cervantes JA, Ramos-Zavala MG, González-Ortiz M, et al Relationship between serum concentration of uric acid and insulin secretion among adults with type 2 diabetes mellitus. Int J Endocrinol. 2011;2011:107904.

13. Garg A. Insulin resistance in the pathogenesis of dyslipidemia. Diabetes Care. 1996;19(4):387-389.

14. Samuel VT, Petersen KF, Shulman GI. Lipid-induced insulin resistance: unravelling the mechanism. Lancet. 2010;375(9733):2267-2277.

15. de Oliveira EP, Burini RC. High plasma uric acid concentration: causes and consequences. Diabetol Metab Syndr. 2012;4:12.

16. Martínez Larrad MT, Lorenzo C, González-Villalpando C. Associations between surrogate measures of insulin resistance and waist circumference, cardiovascular risk and the metabolic syndrome across Hispanic and non-Hispanic white populations. Diabet Med. 2012;29(11):1390-1394. 